David W. Wakerley†, Moritz F. Kuehnel†, Katherine L. Orchard, Khoa H. Ly, Timothy E. Rosser and Erwin Reisner* Christian Doppler Laboratory for Sustainable SynGas Chemistry, Department of Chemistry, University of Cambridge, Lensfield Road, Cambridge CB2 1EW, U.K.

These authors contributed equally to this manuscript.

Summary

Lignocellulose is Earth's most abundant form of biomass and its valorisation to $H_{2}$ is a key objective for the generation of renewable fuels. Solar-driven photocatalytic reforming of lignocellulose to $\mathrm{H}_{2}$ at ambient temperature offers a sustainable route towards this goal, but this reaction is currently limited to noble metal containing systems that operate with low activity under UV light. Here, we report the light-driven photoreforming of cellulose, hemicellulose and lignin to $\mathrm{H}_{2}$ using semiconducting cadmium sulfide quantum dots in alkaline aqueous solution. We show that basic conditions cause these dots to become coated with oxide/hydroxide in situ, presenting a strategy to improve their photocatalytic performance. The system operates under visible light, is stable beyond 6 days and is even able to reform unprocessed lignocellulose, such as wood and paper, under solar irradiation at room temperature, presenting an inexpensive route to drive aqueous proton reduction to $\mathrm{H}_{2}$ through waste biomass oxidation.

Introduction As of 2016 the global consumption of fossil-derived oil has reached 1100 barrels ( $10^{5}$ litres) per second and continues to climb annually. ${ }^{1,2}$ Low-cost fuel cannot be produced at this rate indefinitely, ${ }^{3}$ and securing and combusting crude oil is causing irreversible environmental damage. ${ }^{4}$ Investigations into sustainable alternatives have consequently identified $\mathrm{H}_{2}$ as a promising energy vector, ${ }^{5}$ which can be used directly in an emission-free fuel cell, or as a hydrogenating agent in the 
synthesis of renewable liquid fuel. ${ }^{6}$ To date however, $\mathrm{H}_{2}$ is almost exclusively produced through

27 reforming/gasification of fossil-derived coal, gas or oil. ${ }^{7}$

Biomass conversion is one of the most affordable routes to generate sustainable $\mathrm{H}_{2}{ }^{8}$ but this process requires the demanding chemical transformation of lignocellulose. Lignocellulose is the main constituent of biomass and can be cultivated worldwide, even on unfertilised, marginal land. ${ }^{9}$ Lignocellulose conversion to $\mathrm{H}_{2}$ has predominantly been realised through gasification, which uses high temperatures $\left(>750^{\circ} \mathrm{C}\right.$ ) to decompose its organic structure and release $\mathrm{H}_{2}$, alongside other gases, such as $\mathrm{CO}, \mathrm{CO}_{2}$ and $\mathrm{CH}_{4} \cdot{ }^{10,11}$ In the interest of increasing the selectivity and efficiency of this conversion, it is possible to replace the thermal input with sunlight. Solar light offers an essentially inexhaustible source of globally available energy and therefore the photoreforming of biomassderived compounds is a fast growing field of research. ${ }^{12,13}$

37 Photoreforming requires a photocatalyst able generate holes to oxidise lignocellulose and use the resultant electrons to reduce aqueous protons to $\mathrm{H}_{2}{ }^{12}$ Lignocellulose therefore adopts the role of a hole scavenger, providing a continuous supply of electrons for fuel production. Thus far, this field has focused on $\mathrm{H}_{2}$ evolution from substrates that could be derived from lignocellulose, such as methanol, glycerol or glucose, ${ }^{12}$ but lignocellulose refining is expensive and inefficient, usually requiring acid hydrolysis, enzymatic hydrolysis or pyrolysis to produce more manageable substrates. ${ }^{12}$ Viable $\mathrm{H}_{2}$ production systems must therefore reform lignocellulose directly, to compete with thermochemical processes. ${ }^{14,15}$ This is challenging at ambient temperatures, as the structure of lignocellulose has evolved to prevent its consumption by microbial and animal life. ${ }^{16}$ Lignocellulose is mainly comprised of cellulose ( $>40 \%$ in wood stems), ${ }^{17}$ a crystalline polysaccharide of 47 anhydroglucose monomers (Fig. 1a). Cellulose is surrounded by branched polysaccharides, called 48 hemicelluloses (20-40\%), which are heteropolymers of pentose and hexose sugars. The two cellulosic polymers are further encased in the cross-linked phenolic polymer, lignin $(<35 \%)$, and the combined structures form microfibrils that are resistant to chemical transformation. ${ }^{9}$ Examples of 
(a)
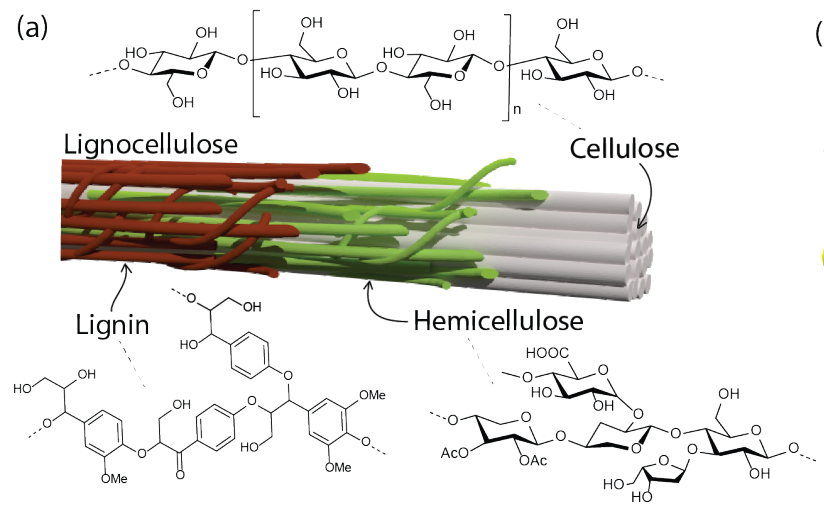

(c) Grass

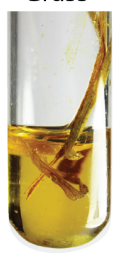

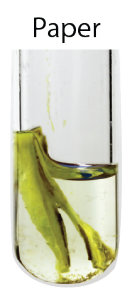

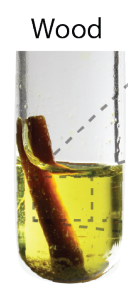

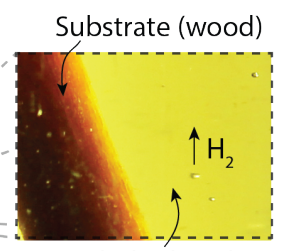

Suspended $\mathrm{CdS} / \mathrm{CdO}_{\mathrm{x}}$ (b)

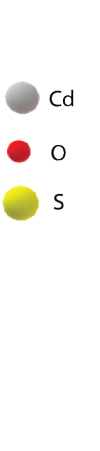

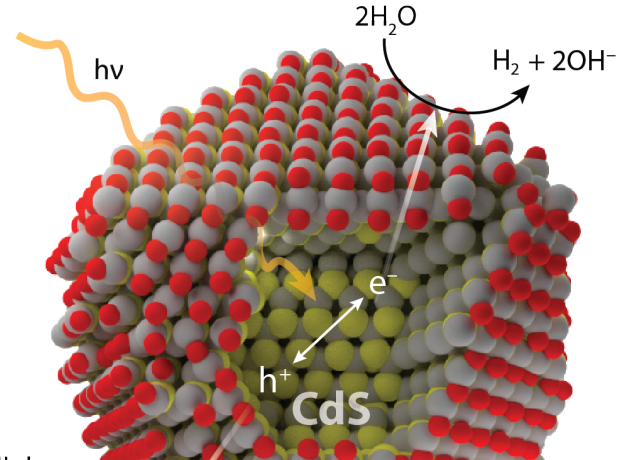

Lignocellulose -

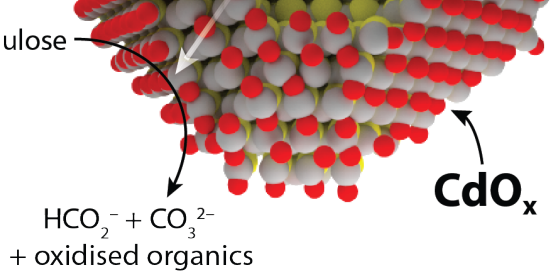

oxidised organics
54

Figure 1 | Photoreforming of lignocellulose to $\mathrm{H}_{2}$ on $\mathrm{CdS} / \mathrm{CdO}_{\mathbf{x}}$. (a) Lignocellulose exists as microfibrils in plant cell walls and is comprised of cellulose surrounded by the less crystalline polymers hemicellulose and lignin. ${ }^{9,15}$ (b) These components can be photoreformed into $\mathrm{H}_{2}$ using semiconducting $\mathrm{CdS}$ coated with $\mathrm{CdO}_{x}$ (the $\mathrm{CdO}_{x}$ surface is believed to contain some $-\mathrm{OH}$ functionality, but $\mathrm{H}$-atoms have been removed in the illustration for clarity). Light absorption by CdS generates electrons and holes, which travel to the $\mathrm{CdO}_{x}$ surface and undertake proton reduction and lignocellulose oxidation, respectively. (c) This combination creates a highly robust photocatalyst able to generate $\mathrm{H}_{2}$ from crude sources of lignocellulose when suspended in alkaline solution and irradiated with sunlight. A video of the photoreforming of paper and wood is provided in Supplementary Video 1.

Herein, we report the development of a photocatalytic system based on semiconducting CdS quantum dots (QDs) able to photoreform cellulose, hemicellulose and lignin into $\mathrm{H}_{2}$ at room 
temperature. CdS is an inexpensive, visible-light absorbing photocatalyst with a bulk electronic band gap of around $2.4 \mathrm{eV}$. The CdS conduction band has a potential of $-0.5 \mathrm{~V} v$ s. the normal hydrogen electrode (NHE), ${ }^{21}$ providing sufficient driving force for proton reduction and is responsible for several of the highest reported rates of photocatalytic $\mathrm{H}_{2}$ evolution. ${ }^{22}$ The CdS valence band, at roughly +1.9 V vs. NHE, is adequate for saccharide oxidation, ${ }^{13}$ but also sufficient for the photooxidation of its constituent sulfide. This photocorrosion has brought the viability of CdS as a sustainable photocatalyst into question, as $\mathrm{H}_{2}$ evolution has depended on the use of easily-oxidised sacrificial reagents. ${ }^{23}$ To circumvent these issues we employ highly alkaline conditions that promote $\mathrm{Cd}(\mathrm{OH})_{2} / \mathrm{CdO}$ (henceforth $\mathrm{CdO}_{x}$ ) formation on the $\mathrm{CdS}$ surface (Fig. 1b). The resultant $\mathrm{CdS} / \mathrm{CdO}_{x}$ QDs are able to undertake photocatalysis without photocorrosion and light-driven $\mathrm{H}_{2}$ evolution is achieved through the oxidation of completely unprocessed lignocellulosic substrates (Fig. 1c, Supplementary Video 1). Lignocellulose is also more easily solubilised at high $\mathrm{pH}^{24}$ and the synergistic interplay between the active photocatalyst formation and the increase in dissolved lignocellulosic substrate produces a system with high rates of $\mathrm{H}_{2}$ evolution.

\section{Characterisation of $\mathrm{CdS} / \mathrm{CdO}_{x}$ Quantum Dots}

$84 \mathrm{CdS} / \mathrm{CdO}_{x}$ was synthesised from ligand-free $\mathrm{CdS}$ QDs with a diameter of circa $5 \mathrm{~nm},{ }^{25}$ as confirmed by transmission electron microscopy (TEM, Fig. 2a,b). The ligand-free CdS is passivated by weaklybound tetrafluoroborate anions and $\mathrm{N}, \mathrm{N}$-dimethylformamide (DMF), presenting an accessible surface that can be modified for improved catalytic activity. ${ }^{25}$ Addition of the QDs to basic solution caused $\mathrm{CdO}_{x}$ to instantaneously form on the particle surface through $\mathrm{OH}^{-}$binding to $\mathrm{Cd}$ surface sites. $^{26}$ This was confirmed using X-ray photoelectron spectroscopy (XPS) of CdS QDs after suspension in various concentrations of $\mathrm{KOH}$. The expected $\mathrm{Cd} 3 d_{5 / 2}$ and $3 d_{3 / 2}$ binding energies for emissions in CdS are 405 and $412 \mathrm{eV}^{27}$ respectively, which were observed in the photoemission spectrum of QDs isolated from a pH neutral solution (Fig. 2c, see Supplementary Figure 1 for $\mathrm{O}$ and $\mathrm{S}$ 
93 spectra). After isolation from $0.1 \mathrm{M} \mathrm{KOH}$ the $\mathrm{Cd}$ emissions tail towards lower binding energies and

94 after isolation from $10 \mathrm{M} \mathrm{KOH}$ the peaks shift $1 \mathrm{eV}$ lower to 404 and $411 \mathrm{eV}$. The lowered binding 95 energy is consistent with $\mathrm{CdO} / \mathrm{Cd}(\mathrm{OH})_{2}$ environments on the $\mathrm{CdS}$ surface at high $\mathrm{pH} .{ }^{28}$ Quantification 96 of $\mathrm{CdO}_{\mathrm{x}}$ through analysis of the O-region of the XPS spectrum was not possible due to large 97 quantities of residual $\mathrm{KOH}$, which dominated the spectrum.

98 Raman measurements provided in situ evidence for the formation of surface-bound $\mathrm{CdO}_{x}$. Under 514 $99 \mathrm{~nm}$ laser excitation, highly resolved off-resonant Raman spectra of ligand-free CdS QDs in $0,0.1$ and $10010 \mathrm{M} \mathrm{KOH}$ aqueous solutions were obtained (Fig. 2d). Vibrational bands at $305 \mathrm{~cm}^{-1}$ and $605 \mathrm{~cm}^{-1}$ 101 were observed that are assigned to scattering and double-scattering on the longitudinal optical 102 phonon of CdS ( $\mathrm{LO}$ and 2LO), respectively. ${ }^{29}$ As the $\mathrm{KOH}$ concentration is increased, a broadening of 103 the LO peak on the low frequency side is observed that cannot be accounted for by the KOH (Fig. 2e 104 and Supplementary Figure 2). Spectral deconvolution by band-fitting analysis revealed contributions 105 from two bands located at $260 \mathrm{~cm}^{-1}$ and $292 \mathrm{~cm}^{-1}$. These can be attributed to $\mathrm{CdO}$ by comparison to a reference spectrum of $\mathrm{CdO}$ (bulk) and literature values. ${ }^{30,31}$ The positions of these bands are slightly lower than those reported for bulk CdO $\left(265-268 \mathrm{~cm}^{-1}\right.$ and $\left.298-305 \mathrm{~cm}^{-1}\right) \cdot{ }^{31}$ Although the 108 formation of $\mathrm{Cd}(\mathrm{OH})_{2}$ was not visible in the Raman spectra (see Supplementary Figure 2 for 109 reference spectrum), this does not confirm that the surface consists solely of $\mathrm{CdO}$, as the dynamic 110 nature of the QD modification would introduce numerous $\mathrm{Cd}-\mathrm{O}$ functionalities. 

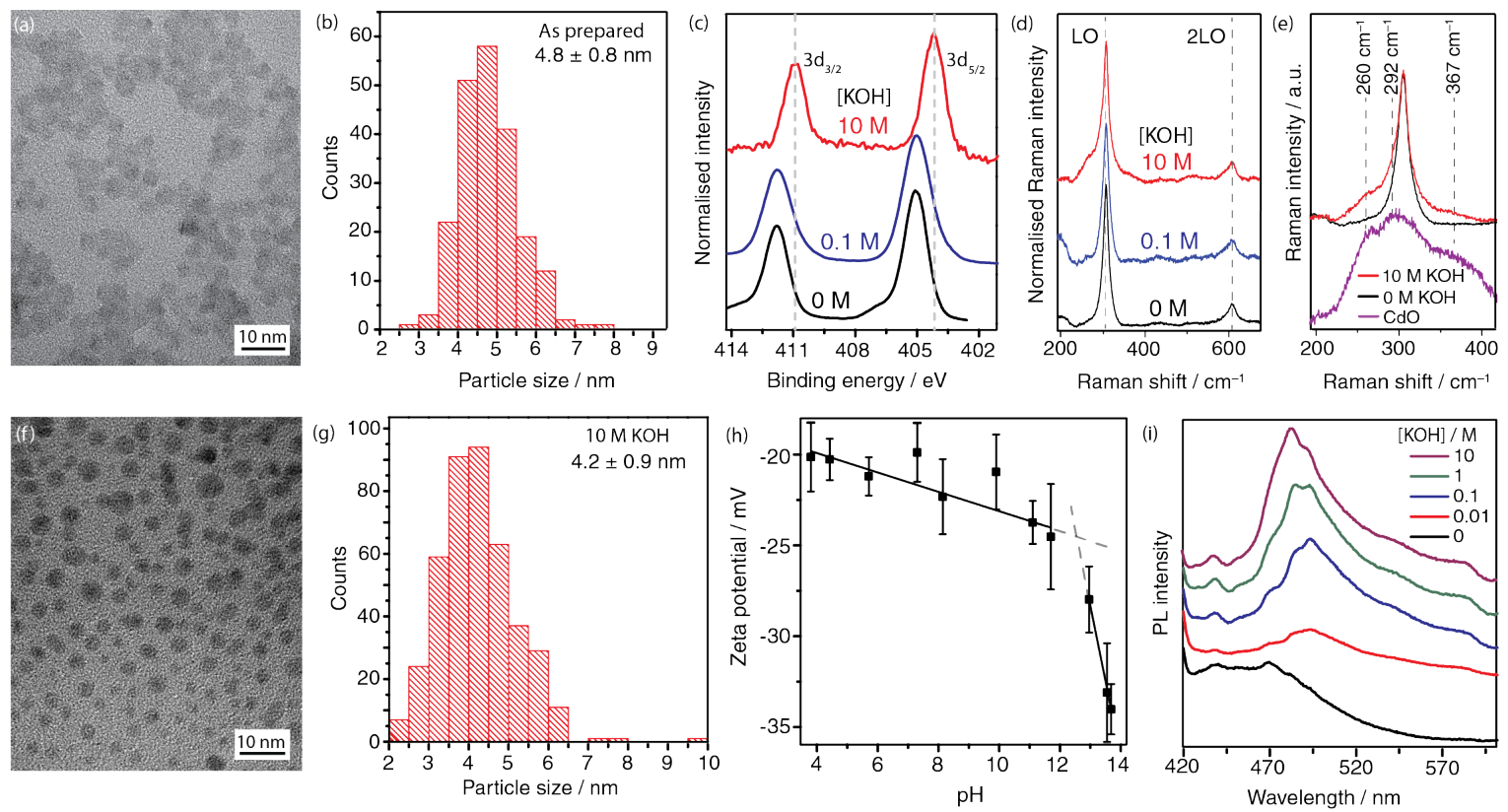

Figure 2 | Characterisation of $\mathbf{C d S} / \mathrm{CdO}_{\mathbf{x}}$. (a) TEM image of ligand-free $\mathrm{CdS}$ QDs and (b) corresponding size distribution. (c) XPS analysis of the $\mathrm{Cd}$ (3d) region of CdS QDs after isolation from aqueous solutions containing various concentrations of $\mathrm{KOH}$. (d) Raman spectra of ligand-free $\mathrm{CdS}$ QDs with $514 \mathrm{~nm}$ excitation at different $\mathrm{KOH}$ concentrations. (e) Raman spectra of ligand-free CdS in $10 \mathrm{M} \mathrm{KOH}$ and in water. In $10 \mathrm{M} \mathrm{KOH}$ an interfering spectral signature of $\mathrm{CdO}$ can be identified. Reference spectrum of $\mathrm{CdO}$ is shown in purple. (f) TEM image of $\mathrm{CdS} / \mathrm{CdO}_{x}$ after isolation from $10 \mathrm{M}$ $\mathrm{KOH}$ and $(\mathbf{g})$ corresponding size distribution. (h) Zeta potential analysis of a solution of CdS QDs (2 $\mu \mathrm{M}$ ) in $0.5 \mathrm{M}$ ionic strength solutions (comprised of $\mathrm{HCl}, \mathrm{KCl}$ and $\mathrm{KOH}$ ) at various $\mathrm{pH}$, showing a substantial increase in negative surface charge above $\mathrm{pH}$ 12. Error bars represent the standard deviation based on 3 measured samples. Two linear fits are shown; one of the data between $\mathrm{pH} 12-$ 14 and another below $\mathrm{pH}$ 12. (i) Photoluminescence emission spectra (excitation/emission bandwidth $=5 \mathrm{~nm})$ at an excitation wavelength of $360 \mathrm{~nm}$ of CdS QDs $(0.5 \mu \mathrm{M})$ in increasingly basic solution. TEM images of $\mathrm{CdS} / \mathrm{CdO}_{\mathrm{x}}$ after isolation from $10 \mathrm{M} \mathrm{KOH}$ show that the surface change occurs with a concomitant decrease in average particle size by $0.6 \mathrm{~nm}$ (Fig. $2 \mathrm{f}, \mathrm{g}$ ). It also causes a change in surface charge as zeta potential analysis of the QDs shows a rapid increase in negative charge above $\mathrm{pH} 12$ 
(Fig. 2h). This shift is similar to that observed on $\mathrm{ZnS} / \mathrm{Zn}(\mathrm{OH})_{2}$ surfaces, ${ }^{32}$ indicating $\mathrm{Cd}-\mathrm{O}^{-}$is forming on the particle surface. The bulk properties of the particle are unaffected, since the X-ray diffraction pattern displays only marginal changes after dissolution in $10 \mathrm{M} \mathrm{KOH} \mathrm{(Supplementary} \mathrm{Figure} \mathrm{3).} \mathrm{The}$ UV-visible spectrum after dissolution in $10 \mathrm{M} \mathrm{KOH}$ also retains the light absorption consistent with CdS QDs, although the spectrum is broadened and red-shifted relative to the spectrum in DMF $\left(\lambda_{\max }\right.$ $=450 \mathrm{~nm}$ in DMF and $470 \mathrm{~nm}$ in $10 \mathrm{M} \mathrm{KOH}$, Supplementary Figure 4a). This red-shift is attributed to

\section{Photoreforming of Cellulose}

To test the efficacy of the $\mathrm{CdS} / \mathrm{CdO}_{x}$ photocatalyst for lignocellulose reforming, we initially focused on the oxidation of its major component, cellulose. We used the most crystalline and unreactive form, referred to as ' $\alpha$-cellulose', as its conversion is most crucial if complete lignocellulose reformation is to be achieved. Photocatalysis was carried out with CdS QDs ( $1 \mathrm{nmol})$ and $\alpha$-cellulose 

suspended in a deaerated aqueous solution $(2 \mathrm{~mL})$ kept at $25{ }^{\circ} \mathrm{C}$, which was irradiated with simulated solar light (AM 1.5G, $100 \mathrm{~mW} \mathrm{~cm}^{-2}$ ). The cellulose exists as a suspension due to its low solubility and optimisation revealed that a loading of $50 \mathrm{mg} \mathrm{mL}^{-1}$ led to the highest photocatalytic activity (Supplementary Table 1). Large volumes of $\mathrm{H}_{2}$ could be produced provided strongly alkaline conditions were employed (Fig. 3a) with the activity rapidly increasing towards $10 \mathrm{M} \mathrm{KOH}$. This concurs with the in situ formation of $\mathrm{CdO}_{x}$ on the QD surface (Fig. 2) and a similar pH dependence was observed when photoreforming other substrates (Supplementary Table 2), as seen in previous CdS-based systems. ${ }^{35} \mathrm{H}_{2}$ evolution by the photocatalyst originates mostly from reduction of aqueous protons, as photocatalysis in $D_{2} \mathrm{O}$ produced $\mathrm{D}_{2}$ and $\mathrm{HD}$ in a $4: 1$ ratio (Supplementary Figure 5). Formation of the latter originates from H/D exchange with cellulose $\mathrm{OH}$ groups. $\mathrm{No}_{2}$ was detected without QDs or light (Supplementary Table 1).

The high concentration of $\mathrm{KOH}$ provides the added benefit of solubilising a portion of the suspended cellulose, as known for aqueous $\mathrm{NaOH} .{ }^{24}$ Dissolved cellulose chains were confirmed to be the major substrate through use of a $10 \mathrm{M} \mathrm{KOH}$ solution that had been stirred in the presence of $\alpha$-cellulose for 24 hours and subsequently centrifuged to remove the suspended, insoluble cellulose. The supernatant was then added to $\mathrm{CdS} / \mathrm{CdO}_{\mathrm{x}} \mathrm{QDs}$ and irradiated (Supplementary Figure 6, Supplementary Table 3). $\mathrm{H}_{2}$ evolution from this solution was initially faster relative to the rate 175 suspended cellulose by the basic solution, followed by its fast oxidation by the $\mathrm{CdS} / \mathrm{CdO}_{x}$ 176 photocatalyst.

177 Long-term photocatalytic $\mathrm{H}_{2}$ evolution from cellulose is illustrated in Fig. 3b. After 6 days there was no evidence of photocorrosion and nearly $600 \mathrm{mmol}_{\mathrm{H}_{2}} \mathrm{~g}_{\mathrm{CdS}}^{-1}$ had been produced in the headspace of a closed photoreactor. The activity of $\mathrm{CdS} / \mathrm{CdO}_{x}$ is over an order of magnitude higher than the 
180 aforementioned $\mathrm{TiO}_{2}$ systems, even without the use of expensive noble metal co-catalysts or UV 181 light. No evolution of $\mathrm{CO}$ was observed during catalysis ( $\mathrm{CO}$ detection limit = $35 \mathrm{ppm}$ ), resulting in $\mathrm{H}_{2}$ 182 free of fuel-cell inhibitors. All $\mathrm{CO}_{2}$ generated was sequestered by the basic solution as $\mathrm{CO}_{3}{ }^{2-}$ (see 183 discussion of Fig. 3c), removing any potential environmental impact of the oxidation reaction. $184 \mathrm{CdS} / \mathrm{CdO}_{x}$ without cellulose present (Fig. 3b, black line) shows $10 \%$ of the $\mathrm{H}_{2}$ evolution activity for the 185 first 24 hours and then ceases (4\% after 6 days), which originates from oxidation of residual DMF 186 from the QD stock solution. The narrower bandgap of CdS also allows the system to function 187 effectively under visible light and $50 \%$ of the catalytic activity was maintained by $\mathrm{CdS} / \mathrm{CdO}_{x}$ when UV188 light $(\lambda<400 \mathrm{~nm})$ was filtered from the solar spectrum (Supplementary Table 1). The drop in activity 189 is due to the decrease in the number of photons, demonstrating that UV-light is not needed to 190 facilitate the photoreforming reaction.

191 An external quantum yield of $1.2 \pm 0.4 \%$ was achieved when irradiating with $430 \mathrm{~nm}$ 192 monochromatic light (Supplementary Table 4), which is comparable to reported efficiencies of $193 \mathrm{Pt} / \mathrm{TiO}_{2}$ for the much simpler glucose reforming reaction under UV-light. ${ }^{36}$ The yield was substantially 194 higher when photoreforming $\mathrm{MeOH}(17.7 \pm 1.5 \%$, Supplementary Table 5$)$, indicating that the 195 efficiency is reduced by the slow oxidation rate of the polysaccharide chains, as well as light196 scattering by the cellulose suspension. 


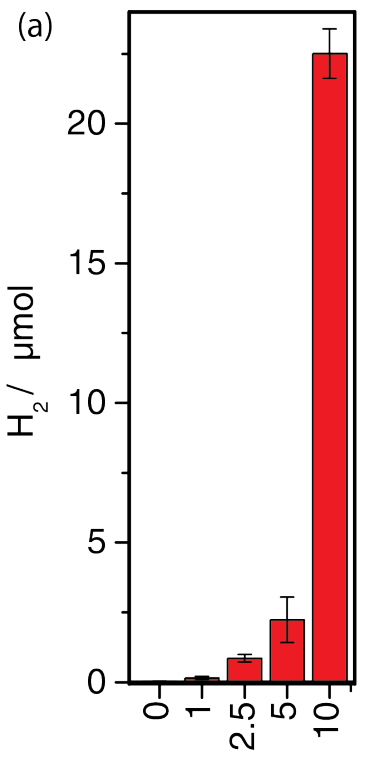

$[\mathrm{KOH}] / \mathrm{M}$

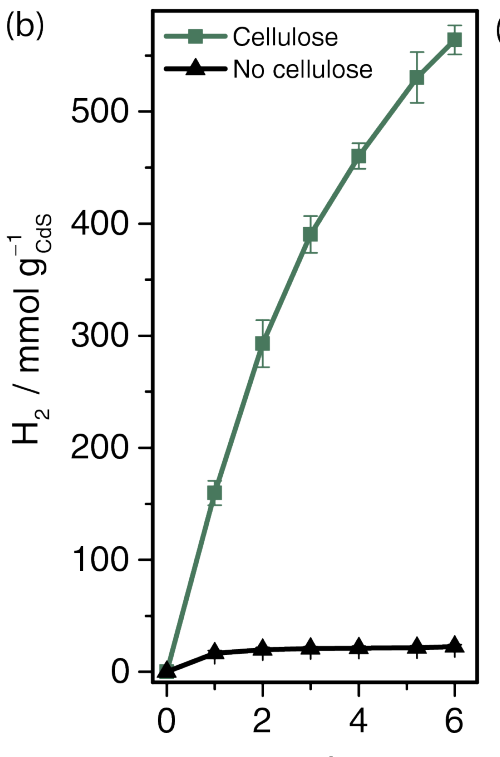

$t /$ days

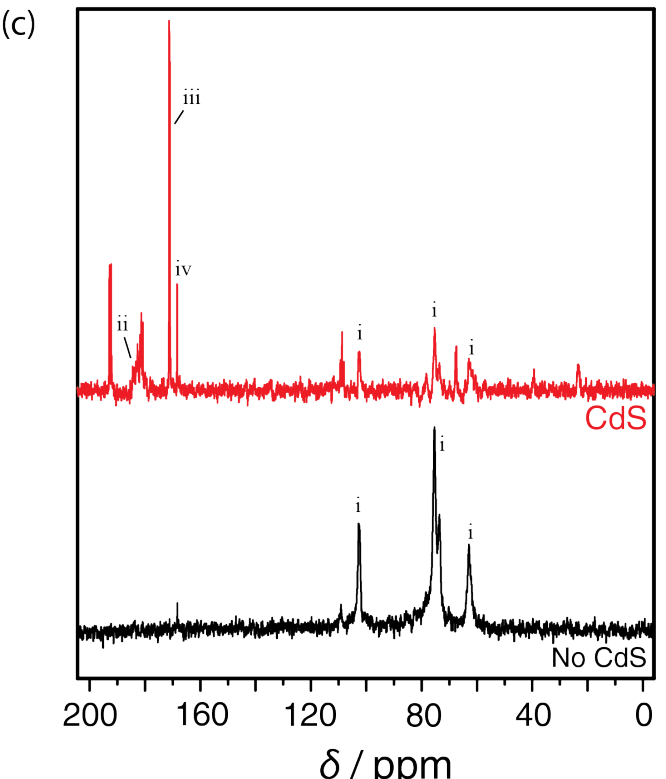

$\delta / \mathrm{ppm}$

Figure 3 | Photoreforming of cellulose to $\mathrm{H}_{2}$ using $\mathrm{CdS} / \mathrm{CdO}_{\mathbf{x}}$. (a) The $\mathrm{pH}$ dependence of the photocatalytic $\mathrm{H}_{2}$ evolution from a $2 \mathrm{~mL}$ aqueous solution of ligand-free CdS QDs (0.5 $\left.\mu \mathrm{M}\right)$ with 50 $\mathrm{mg} \mathrm{mL}^{-1} \alpha$-cellulose after 18 hours of irradiation. (b) Long-term photocatalytic cumulative production of $\mathrm{H}_{2}$ by $\mathrm{CdS} / \mathrm{CdO}_{\times}$QDs $(0.5 \mu \mathrm{M})$ with and without $50 \mathrm{mg} \mathrm{mL}^{-1} \alpha$-cellulose in $2 \mathrm{~mL} \mathrm{KOH} \mathrm{(10}$ M). The line between data points has been added to guide the eye. (c) ${ }^{13} \mathrm{C}-\mathrm{NMR}$ spectra of the supernatant from a suspension of uniformly ${ }^{13} \mathrm{C}$-labelled cellulose $(10 \mathrm{mg})$ in $10 \mathrm{M} \mathrm{NaOD}$ in $\mathrm{D}_{2} \mathrm{O}(1$ $\mathrm{mL}$ ) after 3 days of irradiation with and without $1 \mathrm{nmol}$ of $\mathrm{CdS} / \mathrm{CdO}_{\times}$QDs. Photocatalysis was carried out with simulated solar light (AM 1.5G, $100 \mathrm{~mW} \mathrm{~cm}{ }^{-2}$ ) under an anaerobic atmosphere at $25^{\circ} \mathrm{C}$. Error bars represent the standard deviation based on 3 measured samples.

The products of $\alpha$-cellulose oxidation were identified by ${ }^{13} \mathrm{C}$-NMR spectroscopy using uniformly ${ }^{13} \mathrm{C}$ labelled cellulose in $10 \mathrm{M} \mathrm{NaOD}$ in $\mathrm{D}_{2} \mathrm{O}$ (Fig. 3c). Photocatalysis was carried out with $10 \mathrm{mg}$ of ${ }^{13} \mathrm{C} \alpha-$ cellulose in NaOD for 3 days, after which the reaction solution was filtered of insoluble cellulose and analysed. A control experiment wherein ${ }^{13} \mathrm{C}$-cellulose was irradiated without $\mathrm{CdS} / \mathrm{CdO}_{\mathrm{x}}$ produced signals between $\delta=55-110 \mathrm{ppm}$ (Fig. 3c, black line, i), corresponding to C-environments in the 
213 anhydroglucose repeating unit. ${ }^{37}$ This confirms that the basic conditions are able to partially dissolve the $\alpha$-cellulose, providing solvated cellulose as a substrate for photocatalysis. After irradiation in the presence of $\mathrm{CdS} / \mathrm{CdO}_{\mathrm{x}}$ the polymeric cellulose resonances $(\delta=55-110 \mathrm{ppm}, \mathrm{i})$ are still present, alongside a broad polymeric carboxylic acid resonance ( $\delta=182 \mathrm{ppm}$, ii), from oxidised polysaccharide end groups. ${ }^{38}$ Decomposition of the cellulose by $\mathrm{CdS} / \mathrm{CdO}_{x}$ forms smaller saccharides, however sharp, monosaccharide peaks are not present in the spectrum. This suggests that if smaller saccharides do form they are rapidly consumed by the photocatalyst. The fast affinity of the photocatalyst for smaller saccharide oxidation was confirmed by photoreforming $0.1 \mathrm{M}$ glucose, which produced $\mathrm{H}_{2}$ at a rate of $10.0 \mathrm{mmol}_{\mathrm{H}_{2}} \mathrm{~g}_{\mathrm{CdS}}^{-1} \mathrm{~h}^{-1}$ (Supplementary Table 2); $130 \%$ higher than with $\alpha$-cellulose $\left(4.4 \mathrm{mmol}_{\mathrm{H}_{2}} \mathrm{~g}_{\mathrm{CdS}}^{-1} \mathrm{~h}^{-1}\right)$. In $\mathrm{Pt} / \mathrm{TiO}_{2}$ systems dehydration of monosaccharides produces intermediate furfural species, such as 5-hydroxymethyl furfural (HMF), ${ }^{20}$ however HMF resonances are not visible in the ${ }^{13} \mathrm{C}-\mathrm{NMR}$ spectrum after photocatalysis, (reference spectrum provided in Supplementary Figure 7d). This illustrates that either HMF is not formed or that upon its formation it is rapidly decomposed. The latter is unlikely as photoreforming HMF by the photocatalyst proceeded at a relatively slow rate of $4.7 \mathrm{mmol}_{\mathrm{H}_{2}} \mathrm{~g}_{\mathrm{CdS}}^{-1} \mathrm{~h}^{-1}$ (Supplementary Table 2). Instead, formate was identified as the major intermediate ( $\delta=171 \mathrm{ppm}$, iii), which is a product of biomass oxidation by thermally-driven metal oxide catalysts. ${ }^{39}$ The accumulation of formate was 232 acids and formate oxidation then produces $\mathrm{CO}_{2}$, which was solubilised as carbonate $\left(\mathrm{CO}_{3}{ }^{2-}\right)$ at the employed $\mathrm{pH}$ ( $\delta=169 \mathrm{ppm}$, iv) (Fig. 3c). These assignments were corroborated by reference to authentic samples and ${ }^{1} \mathrm{H}-\mathrm{NMR}$ spectroscopy (Supplementary Figure 7).

${ }^{13} \mathrm{C}-\mathrm{NMR}$ spectroscopy was also undertaken of insoluble cellulose that had been irradiated for 12 hours in $10 \mathrm{M} \mathrm{NaOD} / \mathrm{D}_{2} \mathrm{O}$ both with and without $\mathrm{CdS} / \mathrm{CdO}_{\mathrm{x}}$. The suspended cellulose was collected 
after photocatalysis via centrifugation and dissolved in molten $\mathrm{ZnCl}_{2}$ before measuring a spectrum (Supplementary Figure 7e). ${ }^{40}$ Both spectra showed the expected cellulose resonances, as well as numerous $\mathrm{sp}^{2} \mathrm{C}$-environments. When $\mathrm{CdS} / \mathrm{CdO}_{\mathrm{x}}$ is present there are a number of extra peaks that were assigned to the heterogeneous oxidation of the cellulose. This indicates that there is both homogeneous and heterogeneous oxidation of the cellulose chains during photocatalysis, however due to the mass-transport limitations of the heterogeneous reaction, oxidation of the dissolved cellulose will provide the major contribution to the $\mathrm{H}_{2}$ evolution activity.

Proton reduction is expected to occur on $\mathrm{Cd}$ chalcogenides through $\mathrm{Cd}^{0}$ sites formed by electron accumulation on the photocatalyst surface, ${ }^{41}$ but this leads to slow rates of $\mathrm{H}_{2}$ evolution. Transition metal co-catalysts are thus added to accelerate the proton reduction activity, but showed a limited effect when oxidising cellulose. Addition of $\mathrm{Ni}\left(\mathrm{BF}_{4}\right)_{2}$ lowered the $\mathrm{H}_{2}$ generated and $\mathrm{K}_{2} \mathrm{PtCl}_{4}$ halted resulted in a limited increase in the $\mathrm{H}_{2}$ produced (12\%), but only after several days of photocatalysis (Supplementary Figure 8). XPS analysis of $\mathrm{Co}\left(\mathrm{BF}_{4}\right)_{2}$ in $10 \mathrm{M} \mathrm{KOH}$ showed emissions consistent with $\mathrm{Co}(\mathrm{OH})_{2} / \mathrm{Co}(\mathrm{O}) \mathrm{OH}$ (Supplementary Figure 9$),{ }^{42}$ which is believed to be the co-catalyst in this case. When replacing cellulose with more easily-oxidised glucose the addition of Co ions had a larger influence on the photoactivity, increasing the $\mathrm{H}_{2}$ generated by over $100 \%$ (Supplementary Table 2). The addition of the Co co-catalyst does not have a large influence when cellulose reforming as the cellulose oxidation reaction limits the rate of photocatalytic $\mathrm{H}_{2}$ generation on $\mathrm{CdS} / \mathrm{CdO}_{x}{ }^{43}$

This was further confirmed through studies of the kinetic isotope effect in a solution of $\mathrm{H}_{2} \mathrm{O} / \mathrm{NaOH}$ vs. $\mathrm{D}_{2} \mathrm{O} / \mathrm{NaOD}$. When the rate of reaction is dictated by breaking/making a $\mathrm{H}$-containing bond the activity drops substantially upon changing to deuterated substrates, due to the lower vibrational frequency of the D-containing bond. In the deuterated solvent, the rate of photocatalysis was lowered by only $25 \%\left(k_{\mathrm{H}} / k_{\mathrm{D}}\right.$ of $\left.1.35 \pm 0.16\right)$ (Supplementary Table 7$)$, indicating that the formation/cleavage of an $\mathrm{H}-\mathrm{H} / \mathrm{O}-\mathrm{H}$ bond is not rate-limiting. The limiting oxidation rate is reflected 

(Supplementary Table 8, this data was corrected by background activity and assumes a theoretical maximum of 12 equivalents of $\mathrm{H}_{2}$ form per anhydroglucose monomer). ${ }^{18}$ The relatively low yield is not yet competitive with the conversion attained by thermochemical reforming processes ${ }^{12}$ due to the inaccessibility of the undissolved cellulose.

\section{Photoreforming of Lignocellulose}

Study into the reformation of the other lignocellulose components, lignin and hemicellulose, is presented in Fig. 4a, which shows the $\mathrm{H}_{2}$ evolved per weight of added $\mathrm{CdS}$ and $\mathrm{Co}\left(\mathrm{BF}_{4}\right)_{2}$ co-catalyst (Supplementary Table 9). Hemicellulose (xylan from beech wood) could be reformed at similar rates to $\alpha$-cellulose, as expected from its similar chemical composition. A lowered loading of hemicellulose at $25 \mathrm{mg} \mathrm{mL} \mathrm{m}^{-1}$ was used to reflect the levels of hemicellulose present in lignocellulose. The heightened specific $\mathrm{H}_{2}$ evolution is due to the higher solubility of hemicellulose, which presents more accessible oxidation sites for the particulate $\mathrm{CdS} / \mathrm{CdO}_{x}$ photocatalyst.

Lignin is strongly light-absorbing and consequently its light-driven oxidation to form $\mathrm{H}_{2}$ has rarely been reported. ${ }^{44,45}$ UV-visible spectroscopy of lignin shows a broad absorption peaking at $300 \mathrm{~nm}$ with a shoulder at $350 \mathrm{~nm}$ that tails into visible wavelengths of light, the region over which wideband gap semiconductors absorb most strongly. The smaller band gap of $\mathrm{CdS} / \mathrm{CdO}_{\mathrm{x}}$ absorbs wavelengths above $420 \mathrm{~nm}$, where there is little competition for light between the photocatalyst and substrate (Supplementary Figure 10), allowing photocatalysis to occur effectively. At lignin loadings of $0.25 \mathrm{mg} \mathrm{mL}^{-1}, \mathrm{CdS} / \mathrm{CdO}_{\mathrm{x}}$ was able to evolve $\mathrm{H}_{2}$ at a rate of $0.26 \mathrm{mmol}_{\mathrm{H}_{2}} \mathrm{~g}_{\text {cat. }}^{-1} \mathrm{~h}^{-1}$ (Fig. 4a). The decomposition of lignin during photocatalysis was followed by UV-visible spectroscopy over 5 days of irradiation, which showed a decrease in the peak at $300 \mathrm{~nm}$ and growth of the shoulder at $350 \mathrm{~nm}$ (Supplementary Figure 11a). This change is a result of oxidation of phenols within lignin to quinones. ${ }^{46}$ This also occurred without $\mathrm{CdS} / \mathrm{CdO}_{x}$ present, due to UV-light absorption and selfoxidation by lignin, but 3.7 times slower with no evolved $\mathrm{H}_{2}$ (Supplementary Figure 11b/c). 

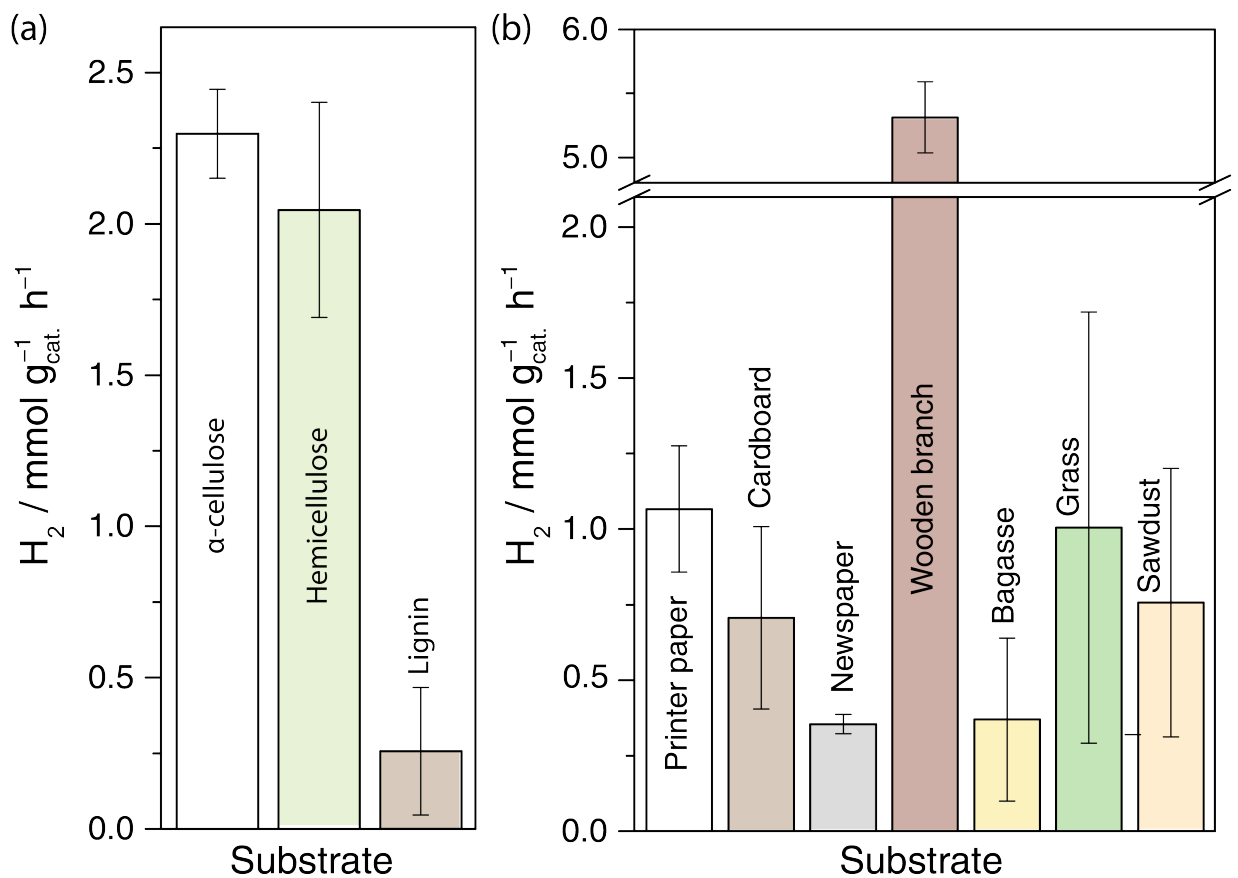

Figure 4 I The rate of $\mathrm{H}_{2}$ generation through photoreforming lignocellulose on $\mathrm{CdS} / \mathrm{CdO}_{\mathrm{x}}$. Photocatalytic production of $\mathrm{H}_{2}\left(\mathrm{AM} 1.5 \mathrm{G}, 100 \mathrm{~mW} \mathrm{~cm}{ }^{-2}\right.$ ) over 24 hours with $\mathrm{CdS} / \mathrm{CdO}_{\times}$QDs $(0.5 \mu \mathrm{M})$ and $\mathrm{Co}\left(\mathrm{BF}_{4}\right)_{2}(0.34 \mathrm{mM})$ in $2 \mathrm{~mL} \mathrm{KOH}\left(10 \mathrm{M}, 25{ }^{\circ} \mathrm{C}\right.$, anaerobic atmosphere) with (a) $50 \mathrm{mg} \alpha-$ cellulose $\mathrm{mL}^{-1}, 25 \mathrm{mg}$ hemicellulose (xylan from beech wood) $\mathrm{mL}^{-1}$ and $0.25 \mathrm{mg}$ lignin $\mathrm{mL}^{-1}$, and (b) $50 \mathrm{mg} \mathrm{mL}^{-1}$ of raw and waste biomass substrates. All values are background corrected by the activity without substrate. Error bars represent the standard deviation based on 3 measured samples.

Solar-driven $\mathrm{H}_{2}$ evolution from unprocessed lignocellulose stands as a long-sought objective for progress in the field of biomass conversion. ${ }^{12}$ Fig. $4 \mathrm{~b}$ (Supplementary Table 10) summarises the rate of $\mathrm{H}_{2}$ evolution from suspensions of raw biomass available in areas local to Cambridge, UK and lignocellulosic waste by $\mathrm{CdS} / \mathrm{CdO}_{x}$ with $\mathrm{Co}\left(\mathrm{BF}_{4}\right)_{2}$ co-catalyst. Each source was added to the reaction mixture after a rough cutting procedure to obtain pieces $<0.25 \mathrm{~cm}$ long and the $\mathrm{H}_{2}$ produced was measured after 24 hours of solar irradiation. Rates of over $5 \mathrm{mmol}_{\mathrm{H}_{2}} \mathrm{~g}_{\text {cat. }}^{-1} \mathrm{~h}^{-1}$ were observed using 
wood from a tree branch, whereas the other natural lignocellulose sources (bagasse, sawdust and grass) exhibited lower activity. Waste paper, cardboard and newspaper were also reformed to $\mathrm{H}_{2}$, despite the highly crystalline cellulose present in their structure. The rate at which $\mathrm{H}_{2}$ is evolved from each substrate competes with the activity of purified monosaccharide reforming systems (typically 1 to $\left.9 \mathrm{mmol}_{\mathrm{H}_{2}} \mathrm{~g}_{\text {cat. }}^{-1} \mathrm{~h}^{-1}\right)^{12}$ and is two orders of magnitude higher than previous reports of

307 photocatalytic lignocellulose reforming. ${ }^{20}$ The high activity is assigned to the employed conditions that benefit both the photocatalyst and the substrate; the alkaline conditions provides an in situ pretreatment of the lignocellulose, dissolving hemicellulose, lignin, cellulose and other saccharides into solution ${ }^{47}$ and also facilitate $\mathrm{CdO}_{\mathrm{x}}$ deposition on the $\mathrm{CdS}$, creating a photocatalyst that is active and robust against corrosion. This provides a one-pot system that is responsive to highly unprocessed substrates, allowing $\mathrm{H}_{2}$ generation from the most ubiquitous lignocellulose in a given area. It should be noted that unreacted biomass remains after 24 hours due to incomplete substrate Mechanism of Lignocellulose Reforming on $\mathrm{CdS} / \mathrm{CdO}_{x}$

317 Photocatalytic lignocellulose oxidation is often believed to occur through the formation of hydroxyl 318 radicals $(\cdot \mathrm{OH})$, which subsequently oxidise the substrate. ${ }^{20}$ This possibility was explored using the $319 . \mathrm{OH}$-scavenger benzene-1,4-dicarboxylic acid (terephthalic acid, TPA). TPA reacts with $\cdot \mathrm{OH}$ to form 2hydroxyterephthalic acid (TPA-OH), which can be characterised by its fluorescence at $430 \mathrm{~nm}$ when 322 levels of TPA-OH formation below pH 14 (Supplementary Figure 12a), typically amounting to $<2$ $\mu \mathrm{mol} \cdot \mathrm{OH}$ when compared to a TPA-OH reference (assuming the reaction yield of $\cdot \mathrm{OH}$ and TPA to be $35 \%,{ }^{48}$ Supplementary Figure $12 \mathrm{~b}$ ). Above $\mathrm{pH} 14$, when $\mathrm{CdS} / \mathrm{CdO}_{x}$ is formed, no TPA-OH was detected and therefore it is unlikely that $\cdot \mathrm{OH}$ plays a dominant role in the presented system. 
326 Function of the probe above and below $\mathrm{pH} 14$ was confirmed through controlled generation $\mathrm{of} \cdot \mathrm{OH}$

327 by $\mathrm{H}_{2} \mathrm{O}_{2}$ photolysis (Supplementary Figure 13). ${ }^{49}$

328 Instead, we propose that the $\mathrm{CdO}_{x}$ coverage promotes effective binding between photocatalyst and 329 the substrate, which would contain numerous alkoxide groups at the employed $\mathrm{pH}$. This interaction 330 may be similar to $\mathrm{TiO}_{2}$, which forms Ti-O-R bonds during photocatalysis, facilitating hole transfer 331 and weakening $\mathrm{C}-\mathrm{C}$ bonds, leading to efficient oxidation to $\mathrm{CO}_{2}{ }^{50}$ Lignocellulosic substrates may 332 bind to the $\mathrm{CdS} / \mathrm{CdO}_{\mathrm{x}}$ surface through analogous $\mathrm{Cd}-\mathrm{O}-\mathrm{R}$ bonds, as evidenced by the formation of 333 the decarboxylation product, $\mathrm{CO}_{3}{ }^{2-}$. Such binding is not normally possible on CdS QDs as available 334 Cd-binding sites are passivated by surface ligands ${ }^{25}$ or sulfide. We therefore speculate that dissolved 335 lignocellulose chains bind to the $\mathrm{CdS} / \mathrm{CdO}_{x}$ surface, allowing the photocatalyst to undertake fast 336 oxidation of alcohols to aldehydes. At this point, $\mathrm{C}-\mathrm{C}$ bond cleavage can generate formate, or the 337 aldehyde can be further oxidised to a carboxylic acid, which is decarboxylated to $\mathrm{CO}_{3}{ }^{2-}$.

338 This reaction almost completely occurs in the homogeneous phase using solubilised lignocellulosic 339 biomass, although a small amount of photoreforming on the surface of insoluble substrates may 340 occur based on ${ }^{13} \mathrm{C}$-NMR evidence (Supplementary Figure 7e). A strong interaction between the $\mathrm{CdO}_{\mathrm{x}}$ 341 surface and insoluble cellulose is also apparent in TEM images after reforming, which show the 342 particles embedded in a cellulose matrix (Supplementary Figure 14). 


\section{Conclusions}

344 We have presented a route to valorise unprocessed lignocellulose to $\mathrm{H}_{2}$ at room temperature using 345 visible light and $\mathrm{CdS} / \mathrm{CdO}_{\times}$quantum dots. This photocatalyst undertakes biomass oxidation, which 346 provides electrons for the reduction of aqueous protons to generate $\mathrm{H}_{2}$. High rates of $\mathrm{H}_{2}$ evolution 347 were achieved, without CdS photocorrosion or noble metal co-catalysts, through use of highly basic conditions that synergistically enabled formation of robust $\mathrm{CdS} / \mathrm{CdO}_{x}$ and dissolution of 349 lignocellulose. The oxidation reaction generates $\mathrm{CO}_{2}$ that is sequestered as carbonate, which leads to 350 an overall negative $\mathrm{CO}_{2}$ balance in the atmosphere when taking into account the $\mathrm{CO}_{2}$ fixation 351 required for biomass growth. The system's tolerance to a range of substrates is particularly 352 appealing for $\mathrm{H}_{2}$ generation without need for lignocellulose processing. Future development should 353 now focus on replacing the $\mathrm{Cd}$ with a more environmentally benign metal.

Methods

Reagents. $\alpha$-cellulose, hemicellulose (xylan from beechwood), lignin (alkali), $\mathrm{CdO}$ and $\mathrm{CdSO}_{4}$ were obtained from Sigma Aldrich and used without further purification. Semiconductor-grade $\mathrm{KOH}$ (Sigma Aldrich, 99.99\%) was used to ensure impurities were not present during photocatalysis. Cobalt(II) tetrafluoroborate hydrate, $96 \%$ (assumed to be $\mathrm{Co}\left(\mathrm{BF}_{4}\right)_{2} \cdot 6 \mathrm{H}_{2} \mathrm{O}$ ) was purchased from Alfa Aesar. NaOD (40 \%wt in $\mathrm{D}_{2} \mathrm{O}, 99 \%$ atom\% $\left.\mathrm{D}\right)$ and $\mathrm{D}_{2}(99.8 \%$ atom $\mathrm{D})$ were purchased from SigmaAldrich. ${ }^{13} \mathrm{C}$ cellulose was purchased from IsoLife. Wood from the branch of a London plane tree was obtained from a tree on Lensfield Road, Cambridge, UK. Sawdust was obtained from a local sawmill (B\&Q, Cambridge) and grass was attained from a garden in North Cambridge. Cardboard was obtained from a Sigma Aldrich box, newspaper from an issue of the Cambridge News, bagasse from a Duni bagasse plate and paper from Office Depot. Waste cellulose and biomass sources were cut 
roughly into pieces $<0.25 \mathrm{~cm}$ long before use. All other reagents were obtained from commercial sources at the highest available purity.

Equipment. UV-Visible spectra were recorded on a Varian Cary 50 UV-Vis spectrophotometer. ${ }^{1} \mathrm{H}$ and ${ }^{13} \mathrm{C}$-NMR spectra were recorded on a Bruker $400 \mathrm{MHz}$ Avance spectrometer at room temperature. Transmission electron microscopy (TEM) images were collected using a FEl Philips Tecnai 20 microscope with $200 \mathrm{kV}$ accelerating voltage. XPS analysis was carried out at the Cambridge Microelectronics centre on a Thermo Scientific ESCALAB Xi ${ }^{+}$XPS Microprobe in an ultrahigh vacuum chamber. Freeze drying was carried out in a VirTis SP Scientific freeze dryer. Powder X-ray diffraction measurements were carried out on an X'Pert PRO diffractometer (PANalytical BV). Photoluminescence measurements were carried out on an Edinburgh Instruments FS5 spectrofluorometer using a $395 \mathrm{~nm}$ long-pass filter to remove scattered light where necessary. $\mathrm{pH}$ was measured on a Mettler Toledo $\mathrm{pH}$ meter and probe, with the exception of the $\mathrm{pH}$ of solutions containing $[\mathrm{KOH}]>1 \mathrm{M}$, which was estimated based on the assumption $\left[\mathrm{OH}^{-}\right] \approx[\mathrm{KOH}]$.

Synthesis of oleic acid capped CdS quantum dots (CdS-OA). CdS-OA were synthesised following a modified literature procedure. ${ }^{51} \mathrm{~A}$ mixture of $\mathrm{CdO}(0.64 \mathrm{~g})$ and oleic acid $(\mathrm{OA}, 29 \mathrm{~mL})$ in octadecene $(89 \mathrm{~mL})$ were heated under an $\mathrm{Ar}$ atmosphere to $280{ }^{\circ} \mathrm{C}$. Separately, a solution of sulfur $(0.08 \mathrm{~g})$ in octadecene $(20 \mathrm{~mL})$ was prepared. Half of the sulfur solution was then added rapidly to the $\mathrm{Cd}$ containing solution and the other half was added continuously over the course of 2 minutes. The vessel was then immediately cooled to $220^{\circ} \mathrm{C}$ with $\mathrm{N}_{2}$ gas and rapidly cooled in a water bath. The solution was diluted with 1:1 hexane:methanol $(100 \mathrm{~mL})$ and the particles were precipitated using excess acetone (c.a. $300 \mathrm{~mL}$ ). Isolation of the particles was achieved by centrifugation at $5000 \mathrm{rpm}$ for $3 \mathrm{~min}$, after which they were re-dispersed in hexane. Two further washing steps were carried out by dispersion in hexane and precipitation with acetone, before finally dispersing in hexane.

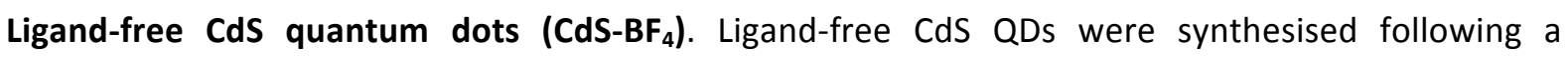
reported literature procedure..$^{25}$ A solution of CdS-OA in hexane $(3 \mathrm{~mL})$ was reduced to dryness and 
re-dispersed in a mixture of anhydrous $\mathrm{CHCl}_{3}(15 \mathrm{~mL})$ and anhydrous $\mathrm{N}, \mathrm{N}$-dimethylformamide (DMF, $1.9 \mathrm{~mL})$ under a $\mathrm{N}_{2}$ atmosphere. $\mathrm{Et}_{3} \mathrm{OBF}_{4}(1.0 \mathrm{M}$ in dichloromethane, $9 \mathrm{~mL})$ was added and the reaction solution was stirred for 1 hour. $\mathrm{Me}_{3} \mathrm{OBF}_{4}(1.0 \mathrm{M}$ in acetonitrile) was added slowly until the particles precipitated (c.a. $3 \mathrm{~mL}$ ). The precipitate was collected by centrifugation (6000 rpm, $3 \mathrm{~min}$ ), and re-dispersed in a minimum of DMF. The QD concentration and particle size was determined by UV-visible spectroscopy based on the position and size of the absorption maximum around $440-450$ $\mathrm{nm}$ in $\mathrm{DMF}^{52}$ All experiments using $\mathrm{CdS}^{5}-\mathrm{BF}_{4}$ in aqueous solution were prepared by first removing the DMF in vacuo while stirring.

Photocatalytic generation of $\mathbf{H}_{\mathbf{2}}$. Photocatalysis was carried out in a Pyrex glass photoreactor thermostated at $25{ }^{\circ} \mathrm{C}$. Solar irradiation was emulated by a solar light simulator (Newport Oriel, 100 $\mathrm{mW} \mathrm{cm}^{-2}$ ) equipped with an air mass 1.5 global filter (AM 1.5G) with a water filter $(10 \mathrm{~cm}$ path length) to remove IR radiation. In a typical experiment ligand-free CdS QDs in DMF (1 nmol) were transferred to a photoreactor and the DMF was removed in vacuo while stirring. Upon removal of the solvent, the substrate and $2 \mathrm{~mL}$ of $10 \mathrm{M} \mathrm{KOH}$ were added. Co-catalyst solutions were made through dissolution of the metal salt in $10 \mathrm{M} \mathrm{KOH}$ and were added to the reaction solution when required. The photoreactor was sealed with a rubber septum and purged with $\mathrm{N}_{2}$ (containing $2 \% \mathrm{CH}_{4}$ for gas chromatographic analysis, see below) for $10 \mathrm{~min}$, after which the vial was irradiated whilst stirring at $600 \mathrm{rpm}$. The accumulation of $\mathrm{H}_{2}$ was quantified through periodic headspace gas analysis $(50 \mu \mathrm{L})$ by gas chromatography.

Gas analysis. Gas chromatography (GC) was carried out on an Agilent 7890A gas chromatograph with a thermal conductivity detector. $\mathrm{H}_{2} / \mathrm{D}_{2}$ were analysed using a HP-5 molecular sieve column (0.32 mm diameter) and $\mathrm{N}_{2}$ carrier gas with a flow rate of approximately $3 \mathrm{~mL} \mathrm{~min}{ }^{-1}$. $\mathrm{CO}$ and $\mathrm{CO}_{2}$ were analysed using a HP-PLOT/Q column ( $0.53 \mathrm{~mm}$ diameter) attached to a HP-5 column $(0.32 \mathrm{~mm}$ diameter) with a He carrier gas at an approximate flow rate of $2 \mathrm{~mL} \mathrm{~min}{ }^{-1}$. The GC oven temperature 
415 was kept at $45{ }^{\circ} \mathrm{C}$ in both cases. Methane $\left(2 \% \mathrm{CH}_{4}\right.$ in $\left.\mathrm{N}_{2}\right)$ was used as internal standard after 416 calibration with different mixtures of known amounts of $\mathrm{H}_{2} / \mathrm{D}_{2} / \mathrm{CO} / \mathrm{CO}_{2} / \mathrm{N}_{2} / \mathrm{CH}_{4}$.

417 Mass spectrometry was carried out on a Hiden Analytical HPR-20 benchtop gas analysis system with 418 custom-designed 8-way microflow capillary inlet to a HAL $101 \mathrm{RC}$ electron impact quadrupolar mass 419 spectrometer with a Faraday detector. The sample inlet was connected to the reactor headspace 420 and the composition of gases with mass/charge ratios between 1 and 10 amu was analysed.

421 Treatment of data. All analytical measurements were performed in triplicate and are given as the 422 unweighted mean \pm standard deviation $(\sigma) . \sigma$ of a measured value was calculated using equation (1).

$$
\sigma=\sqrt{\frac{\sum(x-\bar{x})^{2}}{n-1}}
$$

424 Where $n$ is the number of repeated measurements, $x$ is the value of a single measurement and $\bar{x}$ is 425 the unweighted mean of the measurements. $\sigma$ was increased to $5 \%$ of $\bar{x}$ in the event that the 426 calculated $\sigma$ was below this threshold.

427 The activity per weight of catalyst $\left(\mathrm{mol}_{\mathrm{H}_{2}} \mathrm{~g}_{\text {cat. }}^{-1}\right.$ or mol $\mathrm{H}_{2} \mathrm{~g}_{\mathrm{CdS}}^{-1}$ ) was calculated using equations (2) and 428 (3) from the molar weight of the QD and co-catalyst (when added).

$$
\operatorname{Activity}\left(\mathrm{mol}_{\mathrm{H}_{2}} \mathrm{~g}_{\text {cat. }}^{-1}\right)=\frac{n_{\mathrm{H}_{2}}}{4 / 3 \pi r_{C d S}^{3} N_{a} \rho_{C d S} n_{Q D+n_{\text {co-cat. }} m_{\text {co-cat }}}}
$$

$$
\operatorname{Activity}\left(\mathrm{mol}_{\mathrm{H}_{2}} \mathrm{~g}_{\mathrm{CdS}}^{-1}\right)=\frac{n_{\mathrm{H}_{2}}}{4 / 3 \pi r_{C d S}^{3} N_{a} \rho_{C d S} n_{Q D}}
$$

431 Where $n_{\mathrm{H}_{2}}$ is the $\mathrm{H}_{2}$ produced (mol), $r_{\text {CdS }}$ is the radius of the QD $(\mathrm{cm}), \rho_{\text {Cds }}$ is the density of CdS (4.84 $\mathrm{g}$ $\left.\mathrm{cm}^{-3}\right), N_{a}$ is Avogadro's number $\left(\mathrm{mol}^{-1}\right), n_{Q D}$ is the number of moles of QD (mol), $n_{\text {co-cat. }}$ is the number of moles of added co-catalyst and $m_{\text {co-cat. }}$ is the mass of co-catalyst (taken as $232.54 \mathrm{~g} \mathrm{~mol}^{-1}$ for 
$\left.434 \mathrm{Co}\left(\mathrm{BF}_{4}\right)_{2}\right)$. These values were divided by the irradiation time to calculate mol $_{\mathrm{H}_{2}} \mathrm{~g}_{\text {cat. }}^{-1} \mathrm{~h}^{-1}$ and $\mathrm{mol}_{\mathrm{H}_{2}} \mathrm{~g}_{\mathrm{CdS}}^{-1} \mathrm{~h}^{-1}$.

External quantum yield (EQY) determination. $1 \mathrm{nmol}$ of $\mathrm{CdS}^{-\mathrm{BF}_{4}}$ in $\mathrm{DMF}$ was added to a quartz cuvette (1 cm path length) and evacuated to dryness while stirring. $100 \mathrm{mg}$ of cellulose and $2 \mathrm{~mL}$ of $10 \mathrm{M} \mathrm{KOH}$ were added and the cuvette was sealed with a rubber septum. The solution was purged with $\mathrm{N}_{2}$ containing $2 \% \mathrm{CH}_{4}$ for 10 min in the dark. Each sample was irradiated by a Xe lamp (LOT LSH302) equipped with a monochromator (LOT MSH300) that was used to focus a single wavelength of $430 \mathrm{~nm}$ (accurate to a full width at half maximum of $5 \mathrm{~nm}$ ). The light intensity was adjusted to between $700-800 \mathrm{~mW} \mathrm{~cm}^{-2}$, which was measured using a power meter (ILT 1400, International Light Technologies). The cuvette was irradiated across an area of $0.28 \mathrm{~cm}^{2}$. The evolved headspace gas was analysed by gas chromatography and the EQY (\%) was calculated according to equation (4).

$$
\mathrm{EQY}=100 \times \frac{2 \times n \mathrm{H}_{2} \times N_{A} \times h \times c}{t_{i r r} \times \lambda \times I \times A}
$$

Where $n \mathrm{H}_{2}$ is the amount of $\mathrm{H}_{2}$ generated (mol), $N_{A}$ is Avogadro's constant $\left(\mathrm{mol}^{-1}\right), h$ is Planck's constant $(\mathrm{J} \mathrm{s}), c$ is the speed of light $\left(\mathrm{m} \mathrm{s}^{-1}\right), t_{\text {irr }}$ is the irradiation time $(\mathrm{s}), \lambda$ is the wavelength $(\mathrm{m}), l$ is the light intensity $\left(\mathrm{W} \mathrm{m}^{-2}\right)$ and $A$ is the irradiated area of exposed to the light beam $\left(\mathrm{m}^{2}\right)$.

Raman analysis. Raman spectra were recorded using a confocal Raman spectrometer LabRam (Horiba Jobin Yvon) equipped with a liquid nitrogen cooled Symphony CCD detector (Horiba Jobin Yvon). A $514.73 \mathrm{~nm}$ line of an Ar ion laser (Coherent Innova 300c) was used as excitation wavelength. $10 \mu \mathrm{M} \mathrm{CdS}-\mathrm{BF}_{4}$ QDs in water, $100 \mathrm{mM} \mathrm{KOH}$ and $10 \mathrm{M} \mathrm{KOH}$ were measured in a rotating quartz cuvette. Accumulation time of the Raman spectra was 60 seconds. The laser power was set to $2.5 \mathrm{~mW}$. The laser light was focused into the solution using a 20x objective (Nikon, 20x NA 0.5). $\mathrm{Cd}(\mathrm{OH})_{2}$ was obtained by slowly adding $1.5 \mathrm{~mL}$ of $1 \mathrm{M} \mathrm{NaOH}$ into $10 \mathrm{~mL}$ of a $0.1 \mathrm{M} \mathrm{CdSO}$ solution. $^{2}$ 
The white precipitate was centrifuged and washed with Millipore water $(\rho>18.2 \mathrm{M} \Omega \mathrm{cm})$ three times.

Raman band-fitting analysis. Band fitting of the Raman spectra was employed to evaluate the band structures with low intensities arising at high $\mathrm{KOH}$ concentrations around the LO band at $305 \mathrm{~cm}^{-1}$. For this, the spectra were first cut in the region from $225 \mathrm{~cm}^{-1}$ to $475 \mathrm{~cm}^{-1}$. Then, the spectra of ligand-free CdS in water were fitted. As the LO band dominates the spectra, this band was fitted first using a Lorentzian band profile. The frequency is directly derived from the local maximum in the measured spectrum (i.e. $305 \mathrm{~cm}^{-1}$ ). The band width was adjusted until the experimental band was properly accounted for, affording a width of $13 \mathrm{~cm}^{-1}$, which is comparable to values reported in the literature. Small bands with frequencies around the LO frequency had to be included to enhance the match of generated and experimental spectrum (see Supplementary Figure $2 b$, green dashed lines). These bands do not necessary reflect real bands but may be a result of artefacts due to difficulties in baseline subtraction. The baseline at lower frequencies was dominated by a very strong polynomic increase of intensity towards the Rayleigh line, which made it difficult to properly estimate the baseline. As a result, the band width can be slightly inhomogeneous, which then requires inclusion of smaller bands around the middle frequency to achieve a match with convergence criteria of the fit. Importantly, the intensities of these bands are typically very low compared to the actual band. In this case, the integral intensities are smaller than $5 \%$ and can therefore be neglected.

The spectra of ligand-free CdS in $10 \mathrm{M} \mathrm{KOH}$ were evaluated next using the bands already derived from the water spectra. To reconstruct the spectra properly more bands needed to be included, particularly on the low frequency side of the LO band. To account for the additional spectral contribution, the local intensity maxima were searched for and, at each frequency maximum, an additional Lorentz band was included with a pre-defined width of $20 \mathrm{~cm}^{-1}$. Subsequently, the widths of these bands and their intensities were iteratively altered until the best convergence between overall fit and experimental spectrum was achieved (see Supplementary Figure $2 \mathrm{c}$ ). This set of bands 
481 was then used to fit the $0.1 \mathrm{M} \mathrm{KOH}$ spectra by allowing only the relative intensities of the bands to change. The fit allowed a very good reconstruction of the spectra (see Supplementary Figure 2d).

Zeta potential analysis. A range of aqueous solutions with different $\mathrm{pH}$ values were made through addition of various amounts of $\mathrm{KOH}$ or $\mathrm{HCl}$ to deionised water. The ionic strength of each solution was kept constant at $0.5 \mathrm{M}$ through addition of $\mathrm{KCl} .2 \mathrm{nmol}$ of $\mathrm{CdS}^{-\mathrm{BF}_{4}}$ in $\mathrm{DMF}$ was injected into a vial and dried. $1 \mathrm{~mL}$ of a given solution was added to the vial, the solution was sonicated for $20 \mathrm{~min}$ and the $\mathrm{pH}$ was recorded. Zeta potential was measured in a disposable folded capillary cell on a Malvern Zetasizer Nano Z zeta potential analyser.

X-ray photoelectron spectroscopy. $10 \mathrm{nmol}$ of $\mathrm{CdS}^{-\mathrm{BF}_{4}}$ in $\mathrm{DMF}$ was injected into a vial and the solvent was removed while stirring. $2 \mathrm{~mL}$ of aqueous solution containing various $[\mathrm{KOH}]$ was added and the solution was stirred for $5 \mathrm{~min}$. The particles were isolated from solution through centrifugation $(10,000 \mathrm{rpm}, 10 \mathrm{~min})$, the supernatant was removed carefully and the resultant yellow precipitate was transferred onto a gold-coated silicon substrate and dried. N.B., the dried sample is very hygroscopic; as much supernatant as possible must be removed for the sample to dry effectively.

${ }^{13} \mathrm{C}$-NMR spectroscopy of cellulose. Prior to use, ${ }^{13} \mathrm{C}$-cellulose $(50 \mathrm{mg}$ ) was stirred for $20 \mathrm{~min}$ in $0.1 \mathrm{M}$ $497 \mathrm{NaOH}(10 \mathrm{~mL})$ at $80{ }^{\circ} \mathrm{C}$ in air. The solid was collected by filtration, washed with water $(500 \mathrm{~mL})$ and freeze dried, producing a fine white powder. A photoreactor was charged with $\mathrm{CdS}_{-} \mathrm{BF}_{4}$ in $\mathrm{DMF}$ (1 500 was purged with $\mathrm{N}_{2}$ (cont. $2 \% \mathrm{CH}_{4}$ ) and then irradiated for 3 days. Subsequently, the reaction 501 mixture was filtered through a hydrophilic syringe filter and a ${ }^{13} \mathrm{C}-\mathrm{NMR}$ spectrum was taken of the 502 resultant solution.

To attain a spectrum of the insoluble cellulose, a photoreactor was charged with ${ }^{13} \mathrm{C}$-cellulose $(10$ $\mathrm{mg}$ ) and $10 \mathrm{M} \mathrm{NaOD}$ in $\mathrm{D}_{2} \mathrm{O}(1.0 \mathrm{~mL})$ either with or without $\mathrm{CdS}-\mathrm{BF}_{4}$ QDs $(1 \mathrm{nmol})$. The resultant 
solution was purged with $\mathrm{N}_{2}$ and irradiated, as described above, for 12 hours. Subsequently, the reaction mixture was centrifuged (15 $\mathrm{min}, 12,000 \mathrm{rpm}$ ) and the solid residue was washed with water and freeze-dried to give a pale yellow powder. The yellow powder was added to an NMR tube containing $\mathrm{ZnCl}_{2}(1.00 \mathrm{~g}), \mathrm{LiCl}(200 \mathrm{mg})$ and $\mathrm{D}_{2} \mathrm{O}(360 \mu \mathrm{L}) .{ }^{40}$ The mixture was degassed by three freeze-pump-thaw cycles, sealed and heated to $100{ }^{\circ} \mathrm{C}$ overnight. The resulting brown melt was cooled to room temperature before a ${ }^{13} \mathrm{C}-\mathrm{NMR}$ spectrum was taken.

${ }^{1} \mathrm{H}$-NMR spectroscopy of cellulose. A photoreactor was charged with $\mathrm{CdS}_{-} \mathrm{BF}_{4}(2 \mathrm{nmol})$ and dried. $\alpha-$ cellulose $(100 \mathrm{mg})$ and $10 \mathrm{M} \mathrm{NaOD}$ in $\mathrm{D}_{2} \mathrm{O}(2 \mathrm{~mL})$ were added and the solution was purged with $\mathrm{N}_{2}$ (cont. $2 \% \mathrm{CH}_{4}$ ) and irradiated for 3 days. Subsequently, the reaction mixture was filtered through a hydrophilic syringe filter and $a^{1} \mathrm{H}-\mathrm{NMR}$ spectrum was taken of the resultant solution.

Transmission electron microscopy. $\mathrm{CdS} / \mathrm{CdO}_{\mathrm{x}}$ particles were prepared for $\mathrm{TEM}$ by adding $\mathrm{CdS}-\mathrm{BF}_{4}$ (1.5 nmol) to a vial and drying in vacuo while stirring. Aqueous $\mathrm{KOH}(0.2 \mathrm{~mL}, 10 \mathrm{M})$ was added and the resultant solution was sonicated for $5 \mathrm{~min}$. The suspension was centrifuged at 10,000 rpm for 5 minutes and the supernatant was removed. The particles were re-suspended in diethyl ether (around $1 \mathrm{~mL}$ ) and $10 \mu \mathrm{L}$ of the suspension was loaded onto a CU TEM (TAAB) grid and dried.

Fluorescence quantum yield determination. The absolute fluorescence quantum yield was determined using an Edinburgh Instruments Integrating Sphere Module (SC-30) on an Edinburgh Instruments FS5 spectrofluorometer according to equation (5) and previous reports. ${ }^{53}$

$$
\text { Fluorescence quantum yield }(\%)=\frac{\text { Photons emitted by sample }}{\text { Photons absorbed by sample }} \times 100
$$
To prepare the sample, $\mathrm{CdS}_{-} \mathrm{BF}_{4}(4 \mathrm{nmol})$ was added to a vial and dried in vacuo while stirring. The QDs were then resuspended in $10 \mathrm{M} \mathrm{KOH}\left(3 \mathrm{~mL}\right.$ ) and stirred for 5 minutes. $2.5 \mathrm{~mL}$ of the $\mathrm{CdS} / \mathrm{CdO}_{\mathrm{x}}$ QD solution was added to a quartz cuvette $(1 \mathrm{~cm}$ path length) to make the sample and a $2.5 \mathrm{~mL}$ solution of $10 \mathrm{M} \mathrm{KOH}$ in an equivalent cuvette was used as a reference. The number of photons absorbed by the sample (at $360 \mathrm{~nm}$ ) was determined from the difference in the integrated spectra of 

the excitation beams of the sample and reference solutions. The number of photons emitted by the sample was calculated through the difference of the integrated fluorescence emission of the sample between 440-550 $\mathrm{nm}$ and the reference. Fluorescence spectra analysis software (Fluoracle, Quantum Yield Wizard, Edinburgh Instruments) then gave a value for the quantum yield.

534 The data that support the presented plots within this paper and other findings of this study are 535 available at the University of Cambridge data repository (add link before final publication).

\section{References}

1. U.S. Energy Information Administration. Short-Term Energy and Summer Fuels Outlook. (U.S. Department of Energy, 2016).

2. Tertzakian, P. A Thousand Barrels a Second: The Coming Oil Break Point and the Challenges Facing an Energy Dependent World. (McGraw-Hill Education, 2006).

3. Murray, J. \& King, D. Oil’s tipping point has passed. Nature 481, 433-435 (2012).

4. IPCC, 2013. Climate Change 2013: The Physical Science Basis. Contribution of Working Group I to the Fifth Assessment Report of the Intergovernmental Panel on Climate Change. (2013).

5. International Energy Agency. Tracking Clean Energy Progress 2015 - Energy Technology Perspectives 2015 Excerpt IEA Input to the Clean Energy Ministerial. (2015).

6. Moret, S., Dyson, P. J. \& Laurenczy, G. Direct synthesis of formic acid from carbon dioxide by

548 7. Iulianelli, A., Liguori, S., Wilcox, J. \& Basile, A. Advances on methane steam reforming to 549 produce hydrogen through membrane reactors technology: A review. Catal. Rev. 58, 1-35 (2016).

8. US Department of Energy. Multi-Year Research, Development, and Demonstration Plan - 3.1 

Energy Efficiency \& Renewable Energy, 2015).

9. Rubin, E. M. Genomics of cellulosic biofuels. Nature 454, 841-845 (2008).

10. Huber, G. W., Iborra, S. \& Corma, A. Synthesis of Transportation Fuels from Biomass: Chemistry, Catalysts, and Engineering. Chem. Rev. 106, 4044-4098 (2006).

11. Zinoviev, S. et al. Next-Generation Biofuels: Survey of Emerging Technologies and

18. Zhang, G. et al. Simultaneous cellulose conversion and hydrogen production assisted by Commun. 7, 11162 (2016).

15. Li, C., Zheng, M., Wang, A. \& Zhang, T. One-pot catalytic hydrocracking of raw woody biomass into chemicals over supported carbide catalysts: simultaneous conversion of cellulose, hemicellulose and lignin. Energy Environ. Sci. 5, 6383-6390 (2012).

16. Himmel, M. E. et al. Biomass Recalcitrance: Engineering Plants and Enzymes for Biofuels Production. Science 315, 804-807 (2007).

17. Sun, Y. \& Cheng, J. Hydrolysis of lignocellulosic materials for ethanol production: a review. Bioresour. Technol. 83, 1-11 (2002). cellulose decomposition under UV-light photocatalysis. Chem. Commun. 52, 1673-1676 (2016). 
19. Kawai, T. \& Sakata, T. Conversion of carbohydrate into hydrogen fuel by a photocatalytic

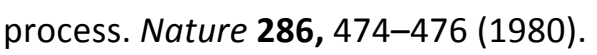

20. Speltini, A. et al. Sunlight-promoted photocatalytic hydrogen gas evolution from watersuspended cellulose: a systematic study. Photochem. Photobiol. Sci. 13, 1410-1419 (2014).

21. Yong, X. \& Schoonen, M. A. A. The absolute energy positions of conduction and valence bands of selected semiconducting minerals. Am. Mineral. 85, 543-556 (2000).

22. Cao, S., Chen, Y., Wang, C.-J., Lv, X.-J. \& Fu, W.-F. Spectacular photocatalytic hydrogen evolution using metal-phosphide/CdS hybrid catalysts under sunlight irradiation. Chem. Commun. 51, 8708-8711 (2015).

23. Xu, Y. et al. Rational design of semiconductor-based photocatalysts for advanced photocatalytic hydrogen production: the case of cadmium chalcogenides. Inorg. Chem. Front. 3, 591-615 (2016).

24. Budtova, T. \& Navard, P. Cellulose in $\mathrm{NaOH}$-water based solvents: a review. Cellulose 23, 5-55 (2016).

25. Chang, C. M., Orchard, K. L., Martindale, B. C. M. \& Reisner, E. Ligand removal from CdS quantum dots for enhanced photocatalytic $\mathrm{H}_{2}$ generation in $\mathrm{pH}$ neutral water. J. Mater. Chem. A 4, 2856-2862 (2016).

26. Spanhel, L., Haase, M., Weller, H. \& Henglein, A. Photochemistry of Colloidal Semiconductors. 20. Surface Modification and Stability of Strong Luminescing CdS Particles. J. Am. Chem. Soc. 109, 5649-5655 (1987).

27. Moulder, J. F., Stickle, W. F., Sobol, P. E. \& Bomben, K. D. Handbook of X-ray Photoelectron Spectroscopy: A Reference Book of Standard Spectra for Identification and Interpretation of XPS Data. (Physical Electronics, 1995).

28. Hammond, J. S., Gaarenstroom, S. W. \& Winograd, N. X-ray Photoelectron Spectroscopic 
600

601

602

603

604

605

606

607

608

609

610

29. Schreder, B. et al. Raman spectroscopy of II-VI semiconductor nanostructures: CdS quantum dots. J. Raman Spectrosc. 34, 100-103 (2003).

30. Kumar, S., Ojha, A. K. \& Singh, R. K. Synthesis and Raman signature for the formation of CdO/MnO2 (core/shell) nanostructures. J. Raman Spectrosc. 45, 717-722 (2014).

31. Cuscó, R. et al. Raman scattering of cadmium oxide epilayers grown by metal-organic vapor phase epitaxy. J. Appl. Phys. 107, (2010).

32. Williams, R. \& Labib, M. E. Zinc Sulfide Surface Chemistry: An Electrokinetic Study. J. Colloid Interface Sci. 106, 251-254 (1985).

33. Kuehnel, M. F., Wakerley, D. W., Orchard, K. L. \& Reisner, E. Photocatalytic Formic Acid Conversion on CdS Nanocrystals with Controllable Selectivity for $\mathrm{H}_{2}$ or CO. Angew. Chemie Int. Ed. 54, 9627-9631 (2015).

34. Dworak, L. et al. Ultrafast Charge Separation at the CdSe/CdS Core/Shell Quantum Dot/Methylviologen Interface: Implications for Nanocrystal Solar Cells. J. Phys. Chem. C 115, 3949-3955 (2011).

35. Simon, T. et al. Redox shuttle mechanism enhances photocatalytic $\mathrm{H}_{2}$ generation on $\mathrm{Ni}-$ decorated CdS nanorods. Nat. Mater. 13, 1013-1018 (2014).

36. Speltini, A. et al. Swine sewage as sacrificial biomass for photocatalytic hydrogen gas production: Explorative study. Int. J. Hydrogen Energy 39, 11433-11440 (2014).

37. Cai, J. \& Zhang, L. Rapid Dissolution of Cellulose in LiOH/Urea and $\mathrm{NaOH} /$ Urea Aqueous Solutions. Macromol. Biosci. 5, 539-548 (2005).

38. Ramos, M. L., Caldeira, M. M. \& Gil, V. M. S. NMR spectroscopy study of the complexation of D-gluconic acid with tungsten(VI) and molybdenum(VI). Carbohydr. Res. 304, 97-109 (1997). 
39. Wolfel, R., Taccardi, N., Bosmann, A. \& Wasserscheid, P. Selective catalytic conversion of biobased carbohydrates to formic acid using molecular oxygen. Green Chem. 13, 2759-2763 (2011).

40. Fischer, S., Leipner, H., Thümmler, K., Brendler, E. \& Peters, J. Inorganic Molten Salts as Solvents for Cellulose. Cellulose 10, 227-236 (2003).

41. Zhao, J., Holmes, M. A. \& Osterloh, F. E. Quantum Confinement Controls Photocatalysis: A Free Energy Analysis for Photocatalytic Proton Reduction at CdSe Nanocrystals. ACS Nano 7, 4316-4325 (2013).

42. Yang, J., Liu, H., Martens, W. N. \& Frost, R. L. Synthesis and Characterization of Cobalt Hydroxide, Cobalt Oxyhydroxide, and Cobalt Oxide Nanodiscs. J. Phys. Chem. C 114, 111-119 (2010).

43. Wu, K. et al. Hole Removal Rate Limits Photodriven $\mathrm{H}_{2}$ Generation Efficiency in CdS-Pt and CdSe/CdS-Pt Semiconductor Nanorod-Metal Tip Heterostructures. J. Am. Chem. Soc. 136, 7708-7716 (2014).

44. Kadam, S. R. et al. A green process for efficient lignin (biomass) degradation and hydrogen production via water splitting using nanostructured C, N, S-doped ZnO under solar light. RSC Adv. 4, 60626-60635 (2014).

45. Li, C., Zhao, X., Wang, A., Huber, G. W. \& Zhang, T. Catalytic Transformation of Lignin for the Production of Chemicals and Fuels. Chem. Rev. 115, 11559-11624 (2015).

46. Müller, U., Rätzsch, M., Schwanninger, M., Steiner, M. \& Zöbl, H. Yellowing and IR-changes of spruce wood as result of UV-irradiation. J. Photochem. Photobiol. B: Biol. 69, 97-105 (2003).

47. Kumar, P., Barrett, D. M., Delwiche, M. J. \& Stroeve, P. Methods for Pretreatment of Lignocellulosic Biomass for Efficient Hydrolysis and Biofuel Production. Ind. Eng. Chem. Res. 48, 3713-3729 (2009). 
48. Fang, X., Mark, G. \& von Sonntag, C. OH radical formation by ultrasound in aqueous solutions Part I: the chemistry underlying the terephthalate dosimeter. Ultrason. Sonochem. 3, 57-63 (1996).

49. Goldstein, S., Aschengrau, D., Diamant, Y. \& Rabani, J. Photolysis of Aqueous $\mathrm{H}_{2} \mathrm{O}_{2}$ : Quantum Yield and Applications for Polychromatic UV Actinometry in Photoreactors. Environ. Sci. Technol. 41, 7486-7490 (2007).

50. Awatani, T., Dobson, K. D., McQuillan, A. J., Ohtani, B. \& Uosaki, K. In Situ Infrared Spectroscopic Studies of Adsorption of Lactic Acid and Related Compounds on the $\mathrm{TiO}_{2}$ and CdS Semiconductor Photocatalyst Surfaces from Aqueous Solutions. Chem. Lett. 27, 849-850 (1998).

51. Huang, L. et al. Dual Cocatalysts Loaded Type I CdS/ZnS Core/Shell Nanocrystals as Effective and Stable Photocatalysts for $\mathrm{H}_{2}$ Evolution. J. Phys. Chem. C 117, 11584-11591 (2013).

52. Yu, W. W., Qu, L., Guo, W. \& Peng, X. Experimental Determination of the Extinction Coefficient of CdTe, CdSe, and CdS Nanocrystals. Chem. Mater. 15, 2854-2860 (2003).

53. Suzuki, K. et al. Reevaluation of absolute luminescence quantum yields of standard solutions using a spectrometer with an integrating sphere and a back-thinned CCD detector. Phys. Chem. Chem. Phys. 11, 9850-9860 (2009).

\section{Supplementary Information}

Supplementary Tables 1-10, Supplementary Figures 1-14 and Supplementary Video 1 are provided in the Supplementary Information. 
669 This work was supported by the Christian Doppler Research Association (Austrian Federal Ministry of 670 Science, Research and Economy and the National Foundation for Research, Technology and 671 Development), the OMV Group (to E.R.), the EPSRC (DTA studentship for D.W.W. and T.E.R), the 672 Isaac Newton Trust, the German Research Foundation (to M.F.K.), the World Premier Institute 673 Research Center Initiative (WPI), MEXT, Japan (to K.L.O.) and a Marie Curie Research fellowship (to 674 K.H.L., GAN 701192 - VSHER). We would like to thank Mr Adam Brown (Cambridge, UK) for 675 performing XPS measurements, Prof. Peter Hildebrandt (TU Berlin, German) for providing access to 676 his laboratory to record Raman spectra and $\operatorname{Dr}$ Benjamin Martindale for proof-reading this 677 manuscript.

680 D.W.W., M.F.K. and E.R. concieved the research. D.W.W. and M.F.K. performed photocatalysis and 681 NMR experiments. D.W.W. and K.L.O. synthesised and characterized the QDs. K.L.O. executed TEM, 682 XRD and the zeta potential analysis. K.H.L. carried out the Raman experiments. D.W.W. and T.E.R. 683 carried out the fluorescence measurements. All authors analysed the data. D.W.W. wrote the 684 manuscript. M.F.K., K.H.L. and E.R. added to the discussion and contributed to the preparation of the 685 manuscript. E.R. supervised the work. 